\title{
ESTIMATING OF OVERSTRENGTH FACTOR OF CONCENTRICALLY X-BRACED STEEL FRAMES
}

\author{
T. Branci ${ }^{1}$ and D. Yahmi ${ }^{2}$ \\ ${ }^{1}$ Departement of Civil Engineering, Hassiba Benbouali University of Chlef \\ Hai Es-Salam, B.P. 151, Route de Senjas, 02000 Ech Chlef, Algeria. \\ e-mail: brancit@yahoo.fr \\ ${ }^{2}$ Departement of Civil Engineering, Hassiba Benbouali University of Chlef \\ Hai Es-Salam, B.P. 151, Route de Senjas, 02000 Ech Chlef, Algeria. \\ e-mail: yahmi_djamel@hotmail.fr
}

Keywords: Frame, Steel, Inelastic Deformation, Overstrength, Brace, Pushover.

\begin{abstract}
The inelastic deformation of structural elements is generally permitted in the case of the design of structures subjected to earthquakes. In this context, the resistance of such structures increases when plastic hinges are formed in their structural elements. The resistance that occurs during the formation of plastic hinges is none other than the overstrength that plays a significant role in the seismic design of structures. As a result, their overstrength and the influence of X-braces on this overstrength are not well understood. This present study tries to evaluate the overstrength factor obtained from inelastic pushover analyses of concentrically X-braced steel frames. The effects of some parameters influencing the value of overstrength factor, including the number of stories, are investigated. The results show that overstrength factor depends closely on this parameter. Finally, based on the findings presented in the study, tentative of overstrength factors are proposed for X-braced steel frames.
\end{abstract}




\section{INTRODUCTION}

The purpose of this work is to study the influence of of x-braces on the structural overstrength in the seismic design of steel structures. Current seismic codes do not mention very clearly the value to be assigned to the overstrength because in reality this one depends on several factors related to the nature and behavior of the material of the structure. After reviewing European (EC8) [1] and Algerian (RPA) [2] code expressions for seismic design base shears, the lateral load responses of four two-dimensional x-braced frames steel structures, designed according to European seismic code, are presented.

\section{OVERSTRENGTH IN SEISMIC DESIGN CODES}

All the seismic codes allow the structures to enter in inelastic range of deformations during the design earthquake, for energy dissipation, introducing the structural behavior factor.

\subsection{Algerian seismic code (RPA99/2003)}

The minimum design base shear, $\mathrm{V}$, required by the Algerian seismic code RPA is:

$$
V=\frac{V_{e}}{R}
$$

where $\mathrm{V}_{\mathrm{e}}$ is the maximum elastic base shear, and $\mathrm{R}$ is the behaviour factor (or reduction factor) of the structure and reflects the capability of a structure to dissipate energy through inelastic behaviour. R depends on the ductility capacity of the structural system and the type of material and was chosen to account for many factors cited in many investigations [3-5]. The magnitude of $\mathrm{R}$ varies from 6 to 2 for steel structures, 5 to 2 for reinforced concrete, 2.5 for masonry, and 2 to 4 for other systems. But the disadvantage of this code is that it gives no precision on the contribution of the overstrength and ductility on the behaviour factor R.

\subsection{European seismic code (EC8)}

The EC8 [1] is based on the capacity design approaches, with its associated procedure in terms of failure mode control, force reduction and ductility requirements. The code suggests the reduction of the design seismic, resulting from idealized elastic response spectra, through the behavior factor generally called the q-factor. For steel structures, the upper value of the behavior factor $\mathrm{q}$ to account for the effects of ductility, redundancy and member overstrength is defined as follow [11]:

$$
q=q_{0} \frac{\alpha_{u}}{\alpha_{1}}
$$

where $\mathrm{q}_{0}$ is the basic value of the behaviour factor, $\alpha_{\mathrm{u}} / \alpha_{1}$ is the overstrength/redundancy coefficient, $\alpha_{\mathrm{u}}$ represents the horizontal force multiplier corresponding to the maximum lateral strength and $\alpha_{1}$ the multiplier corresponding to first yielding in the structure. 


\section{LATERAL CAPACITY}

\subsection{Role of factor $q($ or $R$ ) in design}

Overstrength (or reserve strength) that develops a structure during an earthquake is the most important characteristic of all the others characteristics. As observed after strong earthquakes, It seems that the buildings structures are able to resist forces greater than those for which they were calculated. The presence of significant reserve of strength that was not accounted in design, explains this phenomenon [7]. In this approach, it assumed that the actual strength of structure is higher than the design strength and the structure is able to dissipate energy through yielding. As shown in figure 1, seismic design of structures leads to reducing the forces, $\mathrm{V}_{\mathrm{e}}$, obtained from the linear elastic response spectra by a behaviour factor, q, in European code or coefficient behaviour, R, in Algerian code (or response modification factor in other codes) to achieve design forces. In this figure, the real nonlinear behaviour is idealized by a bilinear elasto-plastic relation. In addition of the overstrength the seismic codes consider a design loads, taking advantage of the fact that the structure possesses significant capacity to dissipate energy (ductility).

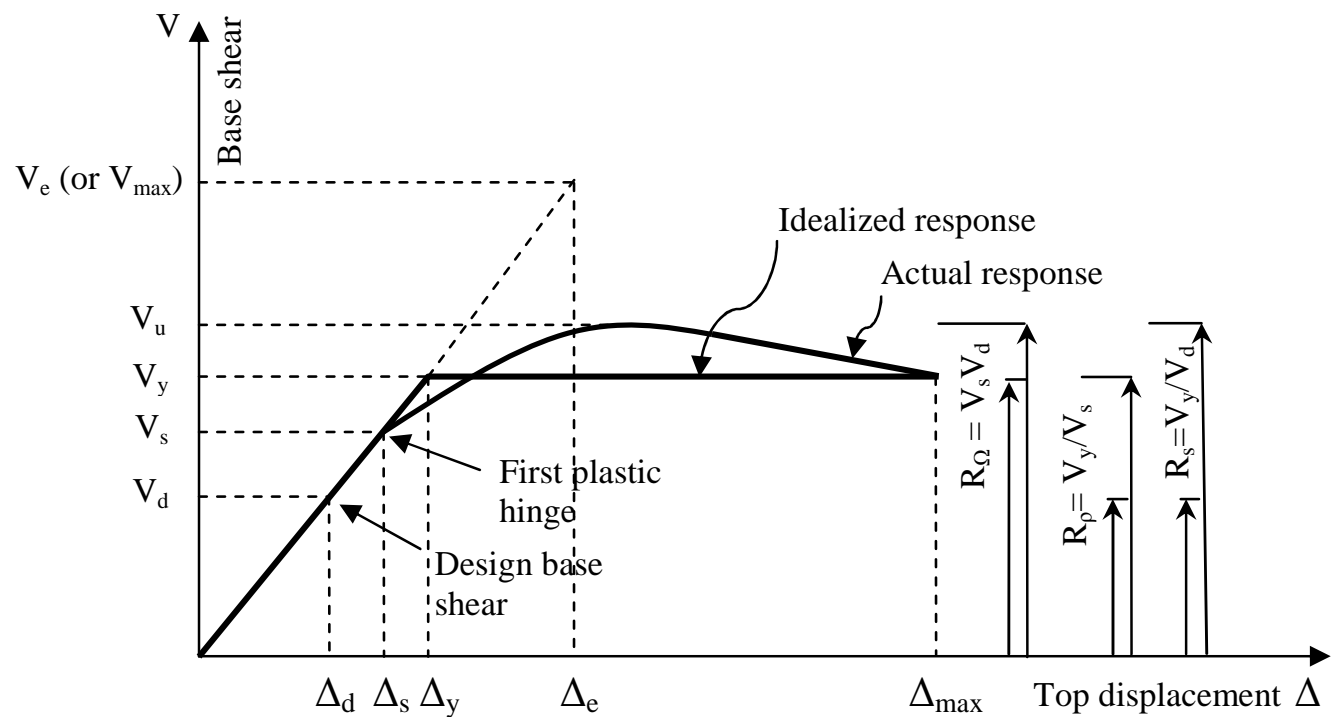

Figure 1: Relation between top displacement and base shear.

\subsection{Relation between $\mathrm{R}$, ductility and overstrength}

According to many researches [6-11], the presence of behaviour factor, $\mathrm{R}$, implies the existence of three different factors $\mathrm{R}_{\mu}, \mathrm{R}_{\rho}$, and $\mathrm{R}_{\Omega}$ :

$$
R=R_{\mu} \cdot R_{\rho} \cdot R_{\Omega}
$$

- The first, $\mathrm{R}_{\mu}$, is the reduction factor due to ductility [7], 12]:

$$
\begin{array}{r}
R_{\mu}=(\mu-1) \frac{T}{T_{C}}+1 \quad \text { if } \mathrm{T}<\mathrm{T}_{\mathrm{C}} \\
R_{\mu}=\mu \quad \text { if } \mathrm{T} \geq \mathrm{T}_{\mathrm{C}}
\end{array}
$$


where $\mathrm{T}$ and $\mathrm{T}_{\mathrm{c}}$ are the fundamental period and the characteristic of ground motion respectively. $\mu$ is the structural ductility factor defined as:

$$
\mu=\frac{\Delta_{\max }}{\Delta_{y}}
$$

where $\Delta_{\max }$ is the maximum displacement and $\Delta_{\mathrm{y}}$ is the yield displacement. Otherwise:

$$
R_{\mu}=\frac{V_{e}}{V_{y}}
$$

- The second, $\mathrm{R}_{\rho}$, is the redundancy factor depending on the plastic redistribution capacity of the structure:

$$
R_{\rho}=\frac{V_{y}}{V_{1}}
$$

- The third, $\mathrm{R}_{\Omega}$, is the overstrength factor and represents the ratio of the lateral strength corresponding to the onset of the first plastic hinge to the one corresponding to the lateral design strength required by code:

$$
R_{\Omega}=\frac{V_{1}}{V_{d}}
$$

where $V_{y}$ is the idealized yield strength, $V_{1}$ is the first significant yield strength and $V_{d}$ the allowable stress design strength.

A strength reduction factor, $R_{s}$, defined as the product between the redundancy factor and the overstrength factor, is expressed as follows:

$$
R_{s}=R_{\rho} \cdot R_{\Omega}=\frac{V_{y}}{V_{d}}
$$

The comparison between equation (2) and equation (3) leads to:

$$
q_{0}=R_{\mu} \cdot R_{\Omega} \text { and } \frac{\alpha_{u}}{\alpha_{1}}=R_{\rho}
$$

\subsection{Factors influencing overstrength due to redistribution}

Overstrength values associated with redistribution of internal forces strongly depend on : 1) structural type, 2) the load combinations, 3) material proprieties, and 4) the criteria used to determine when the ultimate lateral strength is reached [5].

\section{DESCRIPTION OF ANALYTICAL MODELS}

\subsection{Structural system}

In order to assess the range of overstrength associated with redistribution which may present in buildings with concentrically x-braced steel frames (CBFs), a group of such buildings is analyzed. The frames were three, six, nine, and 12 stories tall and were symmetric and regular with the floor plan and geometry illustrated in figure 2 . The storey height was $4.5 \mathrm{~m}$ for the bottom storey and $3.0 \mathrm{~m}$ for all others. The numbers of bays were identical in all frames and were equal to three with $5.5 \mathrm{~m}$ in length. The lateral loads were resisted entirely 
by the perimeter frames and the response of the frame with axis D is considered. Each frame was designed according to European steel design code (EC3) [13] and designed to satisfy the seismic design requirements of EC8 for structures classified as high ductility (DCH) with reference to a PGA of $0.25 \mathrm{~g}$, a soil class A (hard soil type), behaviour factor $\mathrm{q}=6.5$, damping ratio $\xi=5 \%$ and steel members are made of grade $S 275$ steel $\left(f_{y}=275 \mathrm{Mpa}\right)$. Column dimensions are kept larger than beam ones in order take into account capacity design. Gravity loads attributable to frames are evaluated according to conventional design rules, while the lateral loads, assumed to represent the seismic action, are derived using the equivalent static method according to EC8. The member sizes of the frames are provided in table 1. The inelastic static push-over analysis involving P- $\Delta$ effect and using Sap2000 software [14] is employed for obtaining the effects of height on overstrength factors of these steel frames.

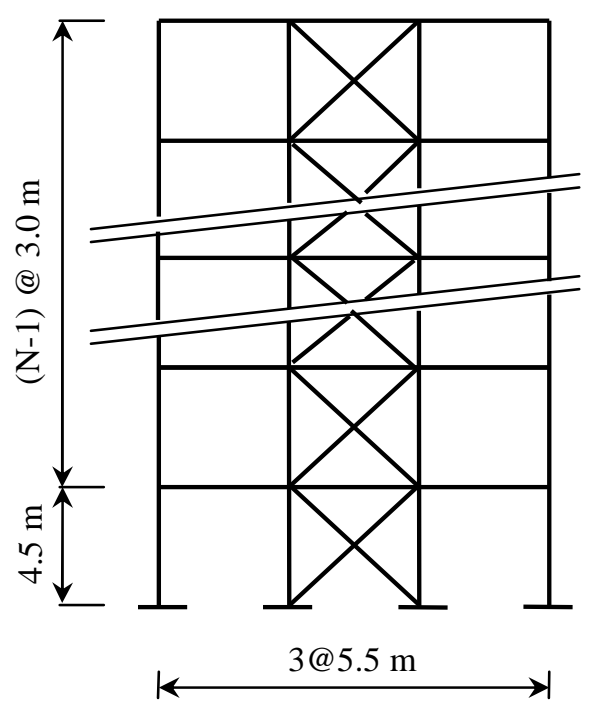

Elevation

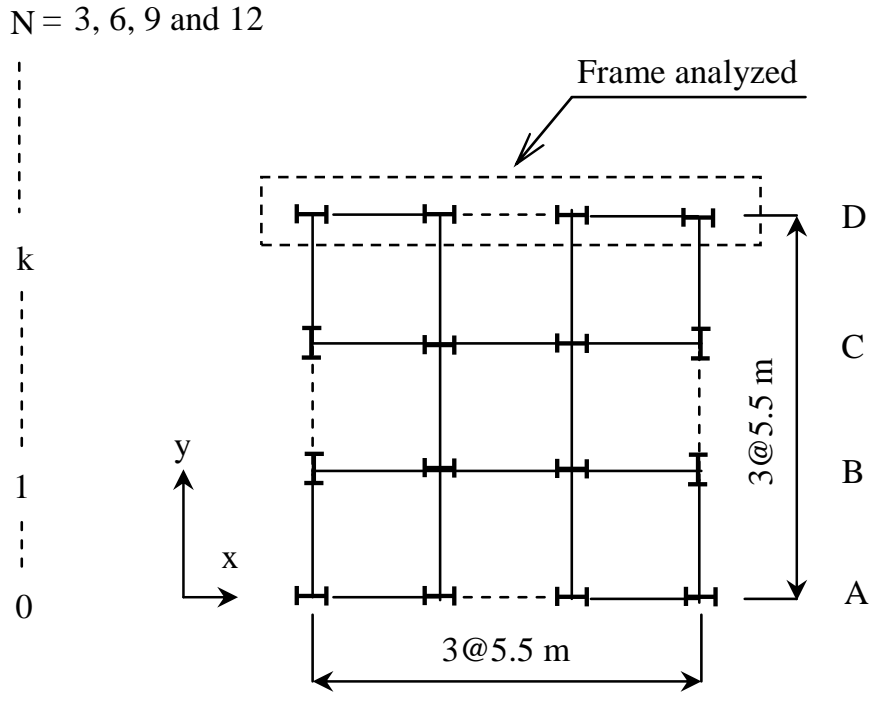

Plan

Figure 2: Configuration of x-braced frames systems.

\begin{tabular}{|c|c|c|c|}
\hline $\begin{array}{l}\text { FRAME } \\
\text { with }\end{array}$ & $\begin{array}{l}\text { COLUMN } \\
\text { HEB section } \\
\left(\mathrm{n}^{\circ} \text { of story) }\right.\end{array}$ & $\begin{array}{l}\text { BEAM } \\
\text { IPE section } \\
\left(\mathrm{n}^{\circ} \text { of story) }\right.\end{array}$ & $\begin{array}{l}\text { BRACE } \\
\text { TUBO section } \\
\left(\mathrm{n}^{\circ} \text { of story) }\right.\end{array}$ \\
\hline 3 stories & $220(1$ to 3$)$ & $300(1$ to 3$)$ & $\begin{array}{l}127 X 4(1), 108 \times 3.6(2), \\
101.6 \times 3.6(3)\end{array}$ \\
\hline 6 stories & $\begin{array}{l}240(1-2), 220(3-4), \\
200(5-6)\end{array}$ & $300(1$ to 3$)$ & $\begin{array}{l}127 \times 4(1-3), 108 \times 3.6(4), \\
101.6 \times 3.6(5), 82.5 \times 3.2(6)\end{array}$ \\
\hline 9 stories & $\begin{array}{l}260(1-3), 240(1-6), \\
220(7-9)\end{array}$ & $300(1$ to 3$)$ & $\begin{array}{l}127 X 4(1-4), 108 \times 3.6(5-6), \\
101.6 \times 3.6(7), 88.9 \times 3.2(8), \\
76.1 \times 3.2(9)\end{array}$ \\
\hline 12 stories & $\begin{array}{l}320(1-3), 300(4-6), \\
280(7-9), 260(10-12)\end{array}$ & $300(1$ to 3$)$ & $\begin{array}{l}127 X 4(1-5), 108 \times 3.6(6-7), \\
101.6 \times 3.6(8-10), 82.5 \times 3.2 \\
(11), 76.1 \times 3.2(12)\end{array}$ \\
\hline
\end{tabular}

Table 1: Dimensions of the members used for the frames. 


\section{EVALUATION AND COMPARISON}

The four frames were subjected to incremental lateral loads using the triangular distribution, which is closer to the first mode distribution. The lateral forces are monotonically increased with a combination of load and displacement control until the target displacement is reached. The target displacement has been considered the 5\% of the total height of the building. The results of the inelastic pushover are present for the fourth frames in figure 3,4 and table 2. The main results of this study can be summarized as follow:

- The three factors, $R_{\rho}$ (redundancy), $R_{\Omega}$ (strength) and their product, $R_{s}$, decrease with an increase in the height of frames. This result was apparent in all frames analyzed.

- The factors, $\mathrm{R}$, are in range of 19 to 4.05 with the average of 8.86. By comparison of these factors with system overstrengh factor suggested by EC8, it is understood that the CBFs-X have higher overstrengh factors.

- With increasing in number of stories the ductility of structure decreases. Therefore, the decrease in ductility causes to decrease the response modification factor, $\mathrm{R}$.

- The ductility factor, $R_{\mu}$, decreases more rapidly compared to overstrengh factor, $R_{\rho}$, with an increase in the number of story.

- In the general state, the overstrengh factor, $R_{s}$ and $R$, for this type of structures (CBFs) is suggested as 3.0 and 6.5 respectively.
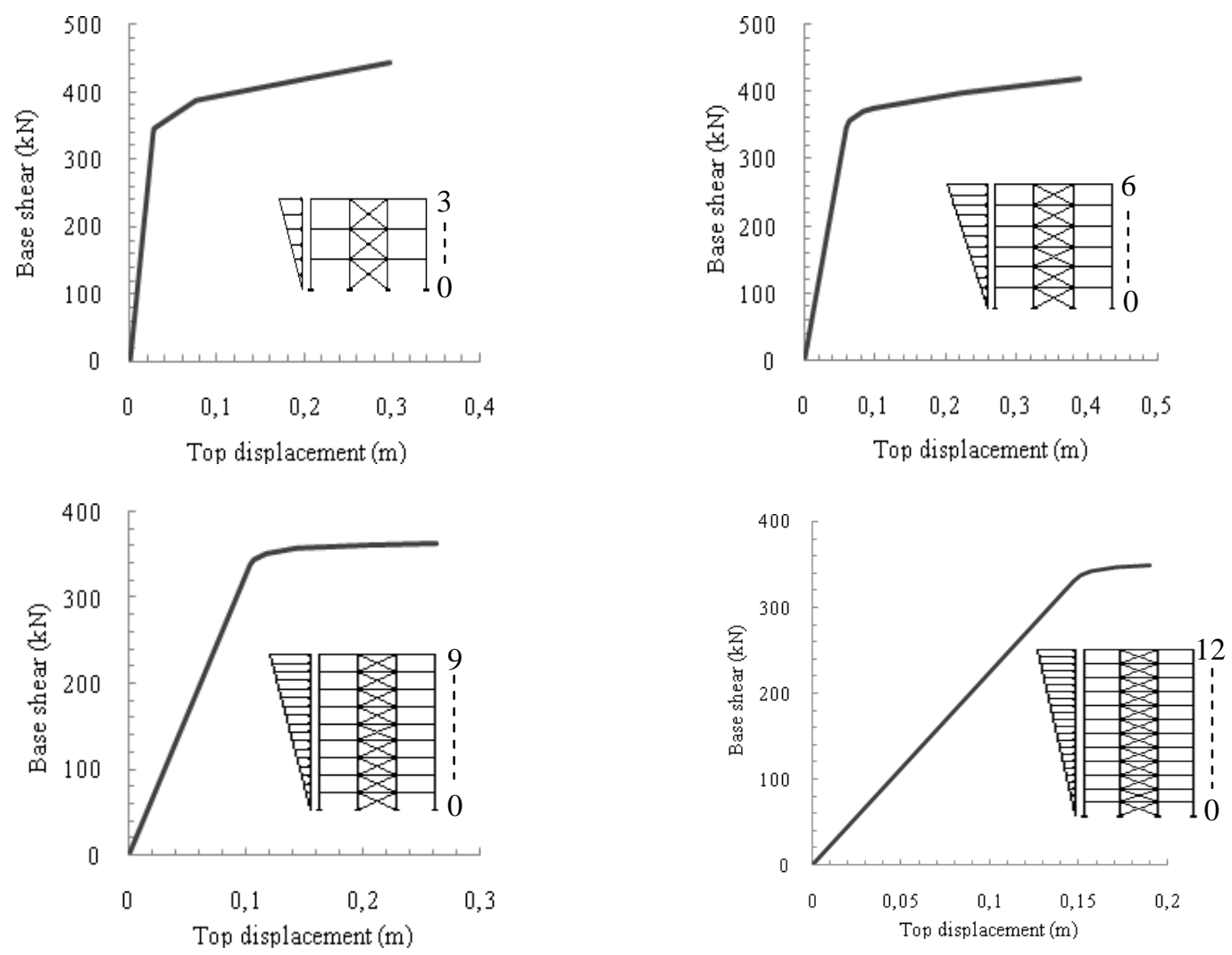

Figure 3: Roof story displacement-base shear curve for frames analyzed. 


\begin{tabular}{llllllllll}
\hline $\begin{array}{l}\text { Frame } \\
\text { With }\end{array}$ & $\begin{array}{l}\mathrm{V}_{\mathrm{y}} \\
(\mathrm{kN})\end{array}$ & $\begin{array}{l}\Delta_{\mathrm{y}} \\
(\mathrm{m})\end{array}$ & $\begin{array}{l}\Delta_{\max } \\
(\mathrm{m})\end{array}$ & $\mu$ & $\mathrm{R}_{\mu}$ & $\mathrm{R}_{\rho}$ & $\mathrm{R}_{\Omega}$ & $\mathrm{R}_{\mathrm{s}}$ & $\mathrm{R}$ \\
\hline 3 stories & 344.37 & 0.028 & 0.297 & 10.6 & 3.23 & 1.80 & 3.25 & 5,85 & 19.0 \\
& & & & & & & & & \\
6 stories & 346.14 & 0.059 & 0.390 & 6.61 & 2.70 & 1.60 & 1.70 & 2,72 & 7,34 \\
9 stories & 339.20 & 0.104 & 0.554 & 5.33 & 2.50 & 1.55 & 1.30 & 2,02 & 5,05 \\
12 stories & 329.71 & 0.147 & 0.659 & 4.48 & 2.25 & 1.40 & 1.25 & 1.80 & 4,05 \\
\hline
\end{tabular}

Table 2: Results of the inelastic pushover analysis.

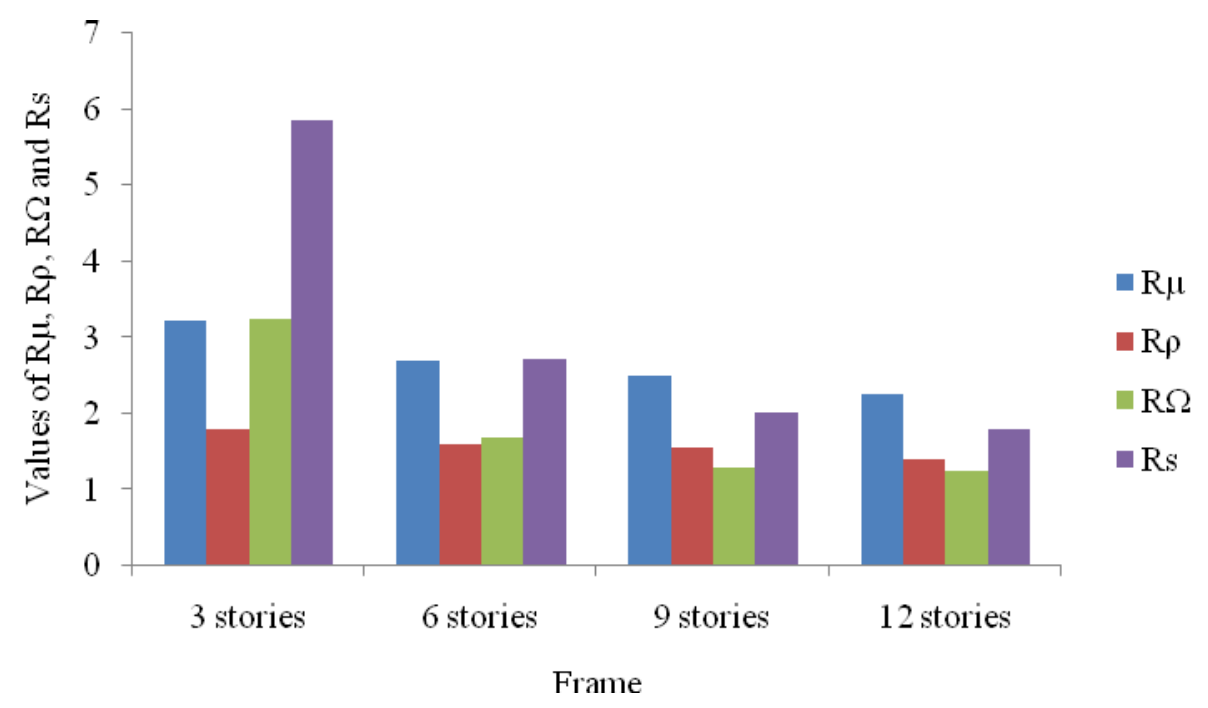

Figure 4: Comparaison between overstrength factors for frames analyzed.

\section{CONCLUSION}

In the present study, the nonlinear response of concentrically x-braced steel frames, from 3 to 12 stories, using the nonlinear analysis program SAP2000 under incremental lateral loading has been carried out with the intention to assess the presence of overstrength attributable to different factors such as ductility, redundancy and overstrengh. The main observations and conclusions drawn are summarized below:

- The ductility, the redundancy and the overstrengh factors decrease with an increase in the number of stories.

- Redistribution of internal forces in the inelastic range due to redundancy in structural system is probably the most dependable estimate of overstrength.

- The global overstrengh due to ductility, redundancy and strength increases with a decrease in the design seismic load.

- Behaviour factor, $R$, for this type of frames is suggested as 6.5. The estimate of this value of $\mathrm{R}$ presented in this study is applicable only for the group of frames analyzed. 


\section{REFERENCES}

[1] EN 1998-1. Eurocode 8: Design of structures for earthquake resistance - Part 1: General rules, seismic actions and rules for buildings, European Committee for Standardization, CEN, 2004.

[2] RPA99/Version 2003, Règles parasismiques Algériennes, Document Technique Règlementaire DTR B C 248, Centre de Recherche Appliquée en Génie Parasismique, Alger, 2003.

[3] A. Osman, A. Ghobarah, R. M. Korol, Implification of design philosophies for seismic response of steel moment frames, Earthquake Engineering and Structural dynamics, 24, 127-143, 1995.

[4] D. Mitchell, P. Paultre, Ductility and overstrength in seismic design of reinforced concrete structures, Canadian Journal of Civil Engineering, 21, 1049-1060, 1994.

[5] M.A. Rahgozar and J.L.Humar, Accounting for overstrength in seismic design of steel structures, Canadian Journal of Civil Engineering, 25(1), 1-15, 1998.

[6] A. Y. Elghazouli, Assessment of capacity design approaches for steel-framed structures, Steel Structures, 5, 465-475, 2005.

[7] M. Mahmoudi, M. Zaree, Determination the modification factors of buckling restrained braced frames, Procedia Engineering, 54, 222-231, 2013.

[8] C. D. Annan, M. A. Youssef, M. H. El Nagger, Assessment of overstrength and ductility of a four-story modular steel building braced frame, $2^{\text {nd }}$ Canadian Conference on Effective Design of Structures McMaster, University Hamilton, Ontario, Canada, May 2023, 2008.

[9] A.S. Elnashai and A.M. Mwafy, Overstrength and force reduction factors of multistory reinforced concrete buildings, The structural design of tall buildings, 11(5), 329-351, 2002.

[10] C. Uang, Establishing R (or $\mathrm{R}_{\mathrm{w}}$ ) and $\mathrm{C}_{\mathrm{d}}$ factors for buildings seismic provisions, Journal of Structural Engineering, ASCE, 117(1), 19-28, 1991.

[11] M. Ferraioli, A. Lavino, A. Mandara, Behaviour factor of code-designed steel momentresisting frames, International Journal of Steel Structures, 14(2), 234-254, 2014.

[12] P. Fajfar, Structural analysis earthquake engineering, A breakthough of simplified nonlinear methods, 12 ${ }^{\text {th }}$ European Conference On Earthquake Engineering, 2002.

[13] EC3, Eurocode 3, Design of steel structures, European Committee for standardization, $1^{\text {st }}$ Draft, prEN 1993-3:2000, $6^{\text {th }}$ December, 2000.

[14] SAP 2000_14.2, Integrated finite element analysis and design of structures reference manual. Berkeley (CA, USA): Computers and Structures INC, 2009. 